\title{
Elementos clave para el realismo de personajes en series de ficción televisiva. Un estudio del caso a través de 'Glee'
}

\section{Key-Elements for Characters Realism in TV Series. A case-study focused on 'Glee'}

\author{
Carlos Fanjul-Peyró. Universitat Jaume I \\ Cristina González Oñate. Universitat Jaume I \\ Francisco Cabezuelo Lorenzo. Universidad de Valladolid
}

Recibido: 30-XI-2014 - Aceptado: 26-III-2015

Resumen:

El aspecto físico y los artefactos son componentes no verbales que desempeñan una función esencial en la definición de roles y personalidades de los personajes de ficción. Si tenemos en cuenta que la base de las primeras impresiones, y el valor comunicativo del aspecto personal, se encuentra en indicios visibles como la apariencia física (forma del cuerpo, atractivo), los artefactos que se utilizan para transformarlo (ropa, peinados, maquillaje y complementos) y la conducta expuesta, no es de extrañar que en las series de televisión se cuiden al máximo estos elementos en aras de ofrecer a la audiencia, desde el primer episodio, una imagen lo más definida y clara del rol que va a desempeñar cada intérprete dentro de la serie y la personalidad de los mismos. En el presente artículo, a partir de una metodología desarrollada 'ad hoc', se analizan estos aspectos en los principales personajes de la serie de ficción televisiva Glee, tomada como caso de estudio, debido a sus numerosos galardones y éxito de audiencias.

Palabras clave:

Aspecto físico, artefactos, comunicación no verbal, casting, credibilidad, Glee.

\section{Abstract:}

The physical appearance and artifacts are nonverbal components that develop a critical role in the definition of roles and personalities of audiovisual fiction characters. Taking into consideration that the base of first impressions, and the communicative value of personal appearance, is the result of visible signs as physical appearance (body shape, physical attractiveness), artifacts that are used to transform it (clothing, hairstyles, make-up and accessories) and the exposed behavior, TV series will set this clear from a very beginning. It is obvious that in television these elements are carefully taken in order to offer to the audience, from the first episode, a clearly and a defined image of the roles. It will play such a big influence on each performance and character. Therefore, this article -with an 'ad hoc' methodology-studies these previous aspects analyzing one by one each of the characters of successful television drama series Glee. It takes the case-study and content analysis as chosen methodology. It has obtained several awards and a great audience success.

Keywords:

Physical appearance, artifacts, nonverbal communication, casting, credibility, Glee. 


\section{Introducción y fundamentos teóricos: el aspecto físico y los artefactos en la comunicación no verbal}

Dentro del estudio de la comunicación humana, autores de la denominada Escuela de Palo Alto (California) como Watzlawick, Beavin y Jackson (2002: 40), definen a la comunicación no verbal (o metacomunicación) como todos aquellos signos y símbolos de naturaleza no lingüística o extralingüística que acompañan, enriquecen o sustituyen a la comunicación verbal. La información proporcionada por gestos, movimientos corporales, aspecto físico, miradas, o incluso el vestuario es esencial para la transmisión de emociones y valores, así como para la correcta interpretación del verdadero sentido y significado de la comunicación (Fanjul-Peyró, 2008: 62)

Los autores de Palo Alto sugieren el estudio de la comunicación humana desde un paradigma sistémico (que integra la sintáctica, semántica y pragmática) caracterizado por la totalidad, la retroalimentación y la equifinalidad, hasta ser acusados en algunas ocasiones de caer en el error de la pancomunicación.

Sin embargo, el modelo de esta escuela pragmática respalda la capacidad de significancia (efecto de sentido que se produce por el juego de los significantes dentro de un enunciado) de la comunicación humana (Eguizábal y Caro, 1996: 133). La significación, entendida como la relación entre un significante y un significado, es esencial para poder transmitir ideas o pensamientos y poder comunicar, pero el sentido de la comunicación se consigue cuando los significantes se unen en una cadena y se entrelazan (efecto recíproco de los significantes o proceso de significancia). "No se trata de realizar una combinación u ordenación mecánica de los elementos, sino de una fusión, de lograr que el conjunto sea superior, diferente a la suma de las partes y que tenga significación" (García, 2003: 17). Investigadores como Birdwhistell y Mehrabian, establecen que los componentes no verbales de la comunicación aportan entre un 65 y un 93 por ciento de información y significación social sobre la verbal.

Dentro de las áreas propias de la comunicación no verbal, el aspecto físico y los artefactos que se utilizan para modificarlo son dos de las que más se han investigado, ya que la imagen externa (proyección social) comunica a los demás una idea de nuestro posible carácter, personalidad y actitud vital. Si alguien va a ser arrojado, introspectivo, fuerte o débil comienza a forjarse en el momento de la percepción física del otro (Knapp, 1995: 174; Lorenzo, 2000: 139 y 167).

En relación con la apariencia y características físicas, se pueden distinguir dos focos de estudio: el rostro y el cuerpo. Ambos aspectos ofrecen valores connotativos que influyen en la construcción de la imagen y en la definición de roles. El atractivo físico de una persona viene determinado, principalmente, por la simetría facial y su constitución corporal: endomorfa (blando, redondo, gordo), mesomorfa (robusto, musculoso, atlético) o ectomorfa (alto, delgado, fibroso).

Sobre la complexión somática, en las sociedades occidentales existen unos modelos estereotipados y socialmente aceptados como ideales. Para los varones, el estereotipo culturalmente establecido ejerce una mayor presión social hacia la potenciación de un cuerpo magro, de músculos definidos (mesomorfo), que aporta una imagen de fuerza, liderazgo y 
valor; mientras que para las mujeres se establece una imagen corporal que mezcla un cuerpo delgado (ectomórfico) con un cuerpo definido y fibrado (mesomórfico), como paradigmas prototípicos de lo que podría denominarse la coalición dominante (Carrillo, Sánchez y Jiménez, 2011: 200-227; Fanjul-Peyró, 2008: 112-119).

Estudios como los de Sheldon y Stevens (1951: 231), Cortés y Gatti (1965: 434) y Bishop (2000: 283-284) establecen una relación entre características físicas y características temperamentales de los individuos. Afables, simpáticos y bondadosos serían los endomorfos; a los mesomorfos los consideran más emprendedores, extrovertidos y enérgicos; y los ectomorfos serían más reflexivos, introspectivos y meticulosos.

Imagen 1

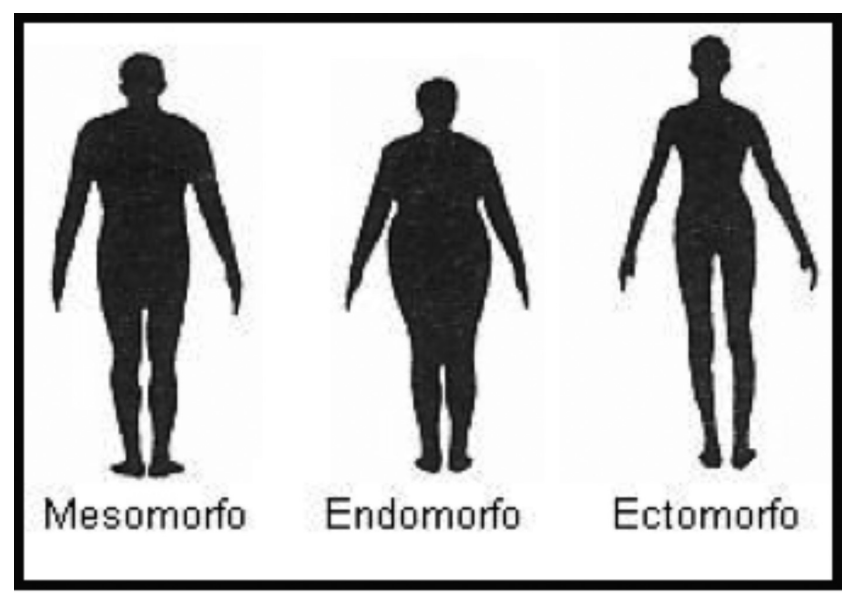

Fuente: Knapp, M. L. (1995): La comunicación no verbal. El cuerpo y el entorno. Barcelona: Paidós, p. 153

La importancia de estos estudios radica en que si existen estos estereotipos en la relación características físicas-temperamento, y son aceptados, se podría explicar por qué los demás nos perciben, reaccionan o esperan que actuemos de una u otra forma, basándose únicamente en la impresión que han tomado de nosotros por nuestras características externas. Bajo esta perspectiva, la estructura física y el temperamento constituirían manifiestamente dos aspectos de la misma realidad y no sorprendería el hecho de suponer que la dinámica de un individuo esté en consonancia con la imagen que éste presenta.

En las preferencias sobre aspectos físicos existen fuertes vinculaciones culturales. La cultura ha establecido patrones idealizados de belleza. El atractivo físico es un montaje social determinado culturalmente y que varía según patrones de estética y tendencias que dicta la moda (Furnham y Alibhai, 1983). "En épocas de carestía, los modelos endomorfos están 
bien vistos, mientras que en épocas de prosperidad se prefieren los modelos ectomorfo y mesomorfo", afirma Pérez Gauli (2000: 63). Además, para otros autores el aspecto físico "ideal” influye sobre el establecimiento de las relaciones sociales y los juicios sobre la propia imagen corporal o la de los demás (Bishop, 2000). Por lo que respecta a las diferencias de género en relación con el atractivo físico, se determina que los conceptos que tienen las personas sobre su propio sexo son mucho más extremistas que los que en realidad el sexo contrario considera como atractivo. Por lo tanto, cada sexo tiene una visión del ideal estético mucho más exigente que la valoración que el sexo contrario hace sobre la misma cuestión.

La belleza física, y en particular la del rostro, es la que en primera instancia despierta una serie de expectativas respecto a los demás. El atractivo facial es el principal elemento que determina la valoración subjetiva de la "belleza" de una persona, de su temperamento y de su posible forma de ser.

Por lo que respecta al atractivo facial, además de la simetría (una persona tiene el rostro simétrico si sus rasgos parecen iguales, equivalentes, equilibrados y virtualmente idénticos a ambos lados), existen otros aspectos que influyen en la percepción de la belleza de un rostro. Para evaluar el atractivo físico facial de los hombres, Cunningham, Barbee y Pike (1990) dividen el rostro masculino en 25 parámetros de estudio.

\section{Imagen 2}

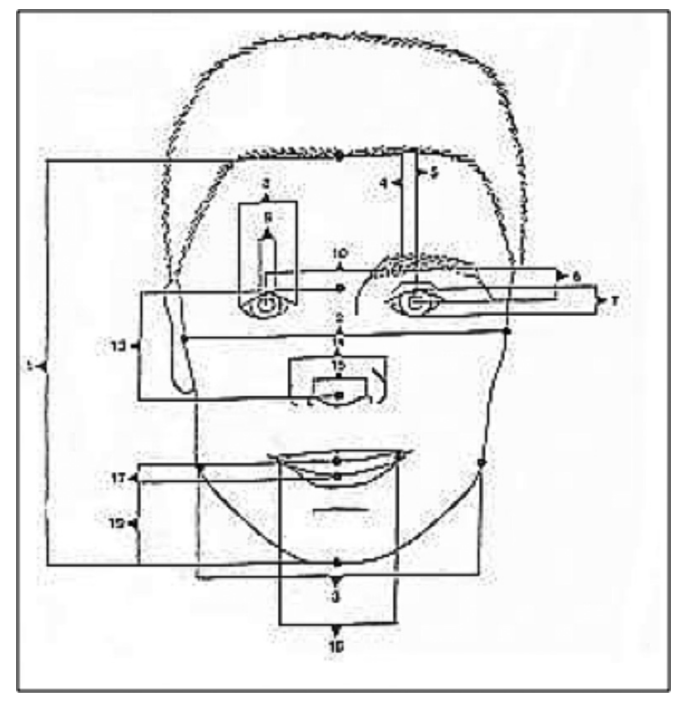

Fuente: Cunningham, M. R., Barbee, A. y Pike, C. L. (1990): “What do women want? Facialmetric assessment of multiple motives in the perception of male facial physical attractiveness", Journal of personality and social psychology,

$$
59 \text { (1), p. } 64
$$


Su investigación consta de tres experiencias diferentes: en la primera, una muestra de cien mujeres debe evaluar cada uno de estos parámetros entre "extremadamente no atractivo" y "extremadamente atractivo" con una escala de ocho puntos; en un segundo análisis, son setenta mujeres las que califican los parámetros del rostro esta vez entre "extremadamente no atractivo/extremadamente atractivo" y "cara de niño/cara madura" en una escala de seis puntos; en la tercera experiencia, un grupo de noventa mujeres debe evaluar los mismos parámetros para "extremadamente no atractivo/extremadamente atractivo", "cara de niño/cara madura”, "cara afeminada/cara masculina”, “cara angular/cara redondeada”, "no deseable/deseable" y "me casaría con él/no me casaría con él” en una escala de siete puntos.

Los resultados de estos estudios indican que: los rostros angulares en los hombres son más atractivos que los redondeados; la región de la nariz es la menos indicativa del atractivo frente a otras como la de los ojos (cejas, párpados), boca y color del pelo; y los rostros intermedios entre cara de niño y madura son los más deseados (incluso para el matrimonio) aunque con más porcentaje de rasgos masculinos que femeninos (Cunningham, Barbee y Pike, 1990: 64-65). Estudios posteriores como los de Hendricks, Olson, Hall y Batt (1998) corroboran las hipótesis establecidas por estos autores sobre el atractivo facial masculino.

La belleza facial femenina estaría definida por una proporción adecuada entre ojos, boca y contorno de cara, ojos grandes, cejas oscuras, pestañas largas y labios carnosos. La preferencia en el rostro es por formas suavizadas, curviformes, despejadas y de pieles limpias, sin excesivas manchas, pecas o lunares (Baudouin y Tiberghien, 2004: 318-320; Fisher y Voracek, 2006: 192). 


\section{Imagen 3}
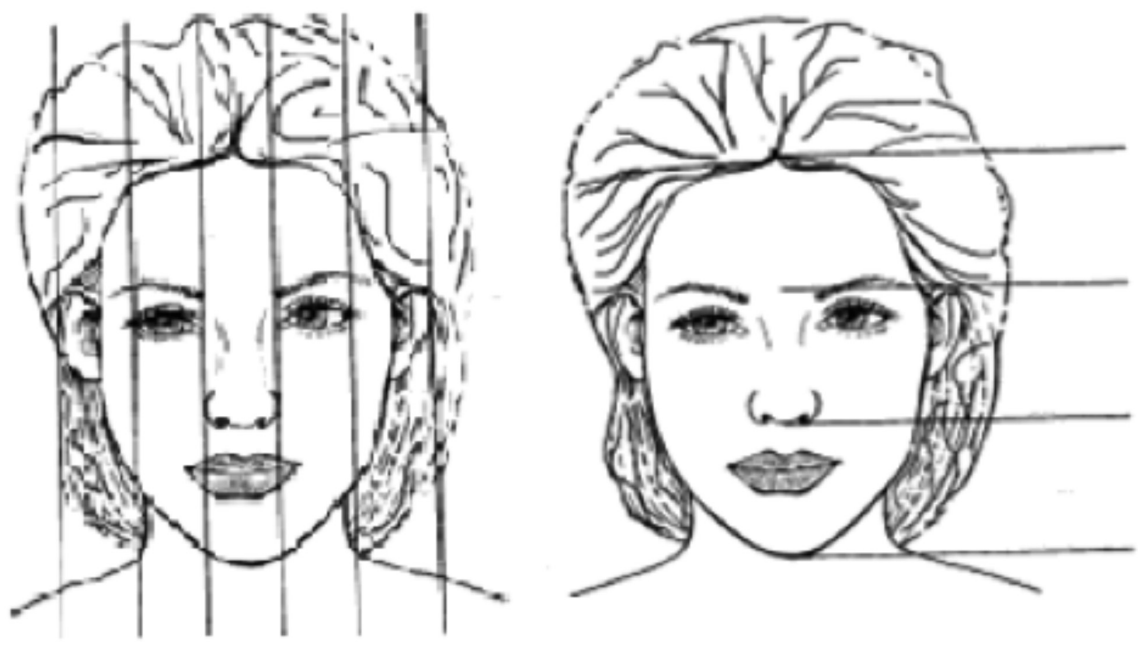

Fuente: Baudouin, J. Y. y Tiberghien, G. (2004): "Symmetry, averageness, and feature size in the facial attractiveness of women”, Acta Psychologica, 117 (3), pp. 313-332

Pallet, Link y Lee (2010) también llegan a estas conclusiones gracias a una investigación en la que solicitaron a estudiantes universitarios que observaran imágenes de rostros femeninos que eran idénticos excepto por ligeras alteraciones en ciertas proporciones faciales (ubicación de los ojos, relación entre los ojos y la boca, etc.). Los rostros femeninos que seguían determinadas proporciones fueron juzgados como más atractivos, concretamente, aquellos que tenían una distancia vertical entre los ojos y la boca del $36 \%$ de la longitud facial y una distancia horizontal entre los ojos del $46 \%$ de la anchura del rostro.

A pesar de ello, hay que tener en cuenta que el aspecto físico puede alterarse o modificarse a través de la utilización de los denominados “artefactos" y, por tanto, variar la percepción y valoración del mismo, así como su capacidad comunicativa y los valores que se le asocian connotativamente.

Se consideran como artefactos todos aquellos elementos que utilizan las personas para modificar su cuerpo y que pueden actuar como estímulos no verbales: la ropa, el maquillaje, los postizos, las gafas y demás complementos. La preocupación por la apariencia personal, los vestidos que se eligen, los peinados que se adoptan y los complementos que se portan son cuidados que tienen carácter comunicativo al poseer la capacidad de transmitir información sobre aspectos tales como personalidad, status social, profesión, identidad, valores y actitudes (comunicación "artifactual”). Son símbolos de lo que se es o de lo que se quiere ser (Pérez, 2000: 51; Deneb, 2001: 198). 
El vestido es uno de los signos de identidad más definidos en la sociedad contemporánea y que ha generado mayor interés a los investigadores en comunicación; en particular, su valor como símbolo de identificación o pertenencia a un grupo social o status determinado. Los uniformes no sólo sirven para determinar la profesión; además transmiten a la persona que los porta una serie de valores y roles que influirán en la actitud, comportamiento y comunicación de los demás. Pero no todos los uniformes son de carácter oficial. Determinado estilo de ropa permite identificarse con grupos urbanos actuando como uniformes "oficiosos", pero que buscan el mismo objetivo: identificarse con un grupo, una manera de actuar y de pensar, así como hacer propios y transmitir a los demás los valores y las connotaciones que esos "uniformes" conllevan (Wainwright, 1991: 117).

En ocasiones, la vestimenta y otros artefactos (anillos, pendientes, piercings, tatuajes) son utilizados no como identificación con un grupo o para la integración social, sino como una actitud de oposición contra lo socialmente correcto o contra las normas sociales que intentan imponer padres o superiores. Algunos jóvenes escogen sus ropas y complementos específicamente porque saben que éstos las considerarán inapropiadas, buscando así reclamar de forma no verbal su independencia o la atención que consideran que se merecen.

Como factor que influye en las interacciones, en la percepción y la valoración del aspecto físico y en la capacidad comunicativa del mismo, la vestimenta y artefactos en general pueden desempeñar diversas funciones tanto físicas (decoración, protección y atracción sexual) como psicológicas (autoafirmación, autogenación, ocultamiento, identificación grupal y exhibición de estatus o rol). Sin embargo, a pesar de su demostrada influencia, los investigadores siguen reclamando que se valore más la relevancia comunicativa que los artefactos poseen (Hervás, 1998: 95; Lorenzo, 2000: 193).

\section{La importancia del casting para la credibilidad de los personajes en series de ficción televisiva}

La cuidadosa preparación y selección del aspecto físico y artefactos de los protagonistas de las series, que se lleva a cabo en los procesos de casting y caracterización, busca aproximarse y alcanzar, en la medida de lo posible, el objetivo, efecto y respuesta deseada junto con la transmisión de valores, ideales y modelos de conducta perseguidos. Todo lo que se dice y lo que no se dice, todo lo denotativo y lo connotativo, todo lo objetivo y subjetivo queda construido y estudiado para conseguir un mensaje claro, directo y persuasivo. Así, el aspecto físico y los artefactos de los personajes de las series de ficción, son elementos propios de la comunicación no verbal que son utilizados para ayudar a definir el papel que va a desempeñar cada actor dentro de la historia televisiva. Son componentes que no se dejan al azar ni se eligen de forma altruista, sino que se tienen muy en cuenta y que vienen determinados en función de la personalidad, actitud, comportamiento y psicología que se ha descrito y que va a desarrollar cada personaje dentro de la trama de la serie.

Detrás de cada uno de estos elementos hay todo un proceso de producción responsable y encargado de la selección de actores (casting), puesta en escena y atrezo, entre otras acciones. Implica muchas horas de trabajo y una gran labor 
profesional en la que se busca adecuar lo más posible los aspectos no verbales que se van a proyectar en la historia que se va a narrar, a la personalidad, valores y seducción con la que se va a dotar al producto audiovisual (Gordillo, 2009: 131; Guerrero, 2004; Garín, 2013: 47-64).

Pasados estudios como los de Mills y Aronson (1965: 73-77), Widgery y Webster (1969: 9-15) o Chen, German y Zaidel (1996: 471-476) ya demostraron que las características físicas de una persona influyen en la capacidad de persuasión y convicción de la fuente y su mensaje. Por tanto, será trascendental la elección adecuada del aspecto físico de los protagonistas principales de una serie para que aporte fuerza, atractivo, credibilidad y veracidad, tanto al personaje como al relato. Esta capacidad no verbal del aspecto físico, dentro de la intencionalidad de la ficción audiovisual, deriva en la importancia que se le otorga a los procesos de selección y casting de actores/modelos para protagonizar series de televisión.

La correcta simbiosis entre el aspecto físico y el carácter del personaje es una pieza más en la clave del éxito de una serie; la apariencia somática y facial es lo primero que van a percibir los espectadores sobre los personajes y, con ella, ya se comienza a forjar en la mente de los mismos una primera impresión de cómo pueden ser cada uno de ellos y qué rol pueden llegar a desempeñar dentro de la historia.

Los relatos protagonizados por hombres y mujeres exigen un especial cuidado de todos los aspectos no verbales que van a rodear a los personajes porque estos elementos modifican y completan el significado y la simbología comunicativa. El aspecto físico de los protagonistas de la narrativa audiovisual tiene especial relevancia para la adecuada percepción e imagen de los personajes de las series. Es un elemento muy estudiado y perfeccionado a través de los artefactos que los protagonistas van a utilizar, buscando siempre la mayor adecuación posible con el mensaje, valores y connotaciones que se pretenden transmitir. Todo queda cuidadosamente medido y preparado para, paradójicamente, conseguir parecer lo más natural y espontáneo posible, dándole así mayor credibilidad a la historia y facilitar la aceptación e identificación con los personajes (Cassetti y DiChio, 1999: 311-312; Fanjul-Peyró y González Oñate, 2012: 80-81).

En este sentido, los responsables de casting buscan seleccionar a aquellos actores que por su aspecto físico se adecuen más al modelo estándar o rol que se quiere plasmar y transmitir. Los procesos de selección tendrán en cuenta tanto los objetivos perseguidos por los responsables de la producción y realización de la serie como el público objetivo al que va dirigida la misma, para dar con el personaje/s más acorde/s a la intencionalidad buscada. La identificación con los protagonistas, así como la familiaridad y simpatía que despiertan, busca la aceptación positiva del receptor en aras de consolidar el éxito y continuidad de la serie televisiva.

Finalmente, destaca la necesaria labor de los profesionales de caracterización que cuidan y estudian los artefactos que los protagonistas de las series utilizan en cada momento. El vestuario y los accesorios (gafas, bolsos, joyas, maquillaje) modifican el aspecto físico y añaden nuevos valores y características que influyen en la transmisión y percepción global 
del mensaje (Cabezuelo Lorenzo, 2010: 97-117). Se eligen cuidadosamente las ropas (formas, corte, colores...), peinados, anillos, collares, pendientes, relojes y demás complementos que van a definir al personaje, determinar su rol (clase social, forma de ser, etc.), dotarlo de credibilidad y situarlo en un ámbito determinado (Knapp, 1995: 165-173; Rosales, 2002: 84). La correcta elección de los artefactos favorecerá el proceso de significación de la producción audiovisual, complementándola y canalizándola.

\section{Glee: características físicas y artefactos que definen la personalidad y los roles de sus protagonistas}

El siguiente análisis, que cuenta con una metodología propia 'ad hoc', elaborada tras el anterior marco teórico y conceptual, parte de una idea muy clara para explicar la calidad de la serie "Glee". Tal y como afirma Joan Costa (2008:107), en el arte, ninguna imagen es subjetiva ni objetiva. Todas ellas son "intersubjetivas". Es decir, el espectador de una obra es quien crea y recrea esa obra en su mente, en su interior. La interioriza, tal y como defienden autores como Marcel Duchamp y André Malraux.

No podemos olvidar que las imágenes poseen una doble naturaleza. Por un lado, está su naturaleza física, gracias a la cual existen, se hacen visibles, circulan y se conservan. Pero, por otro lado, está la naturaleza semiótica de las imágenes, como símbolos. Es lo que en las imágenes es representado o evocado, lo que significan y nos transmiten en un contexto sociológico, cultural, económico e histórico determinado (Lanuza Avello, 2011). Ahí está el poder social de las imágenes. Y en este ahí también radica el éxito de la serie, ya que para muchos críticos estos años suponen una segunda edad de oro de las series de televisión.

Igualmente, este texto parte de la idea de que el significado que una imagen u otra creación audiovisual transporta es compartido, al menos en teoría, entre el autor del mensaje, que diseñó el mensaje con una intencionalidad comunicativa, transmisora de emociones, información, sentimientos o simplemente datos, y el receptor que contempla esa imagen que la acepta de su propia subjetividad.Para ello, este trabajo parte de los presupuestos ya fijados por otros autores sobre la Retórica de la Comunicación de Masas (Serrano Oceja, 2012: 683-698 y Albaladejo Mayordomo, 2013: 21) y la Narrativa y Persuasión Audiovisual (Fernández Díez y Martínez Abadía, 1999; García García, 2006; Canet, 2009 y Gordillo, 2009: Segado Boj y Barquero Cabrero, 2013).

Bajo estos fundamentos teóricos, se toma como caso de estudio para este artículo la primera temporada de la serie estadounidense "Glee", ya que se trata de una comedia dramática musical de reconocido éxito que se comenzó a emitir en mayo del 2009 por la cadena estadounidense Fox. Desde su estreno, la serie ha obtenido premios tales como el Globo de Oro a la mejor serie musical o comedia y diversos premios Emmy. Actualmente, sigue cosechando numerosos premios y reconocimientos que avalan y corroboran su éxito. "Glee" ofrece un perfecto ejemplo de estudio sobre la concordancia entre personalidad, forma de ser y actitud vital de los personajes, con el aspecto físico y uso de artefactos de los mismos, 
dotándolos de credibilidad y empatía que el público reconoce y valora. Como afirma Juan Orellana (2012: 1159), gracias a la ficción audiovisual, "se abre un abanico de variedades narrativas que a menudo han tratado de huir de los patrones más convencionales para encontrar formas de revelar lo humano más indirectas, menos inmediatas, pero intencionalmente más auténticas".

La dificultad añadida en los procesos de selección de los protagonistas de esta serie radica en que se tenían que elegir a actores jóvenes que, además de adecuarse físicamente al personaje descrito en la serie y empastar con la personalidad del mismo, debían saber cantar y bailar en sus interpretaciones. Son personajes que actúan en un escenario multiprotagonista y coral representando lo que algunos teóricos interpretan como historias de "lotta-continua" y "multi-protagonista" (Martínez Lucena, 2009).

Concebida inicialmente como película por Ian Brennan, fue convencido por los directores-creadores Ryan Murphy y Brad Falchuk de que el concepto funcionaría mejor como serie de televisión. La contextualización e historia que presenta Glee no deja de ser un clásico de producciones americanas: un grupo de chicos de instituto que intentan encajar y ser aceptados dentro de las jerarquías y status que se establecen entre los alumnos de instituciones de enseñanza pública. Sin embargo, sus diferentes personalidades y su gusto por la música choca con las normas establecidas, generando el rechazo y la burla de sus compañeros. El único sitio donde encontrarán refugio y se sentirán libres, aceptados y realizados será en el Glee Club.

Tomando como referencias los estudios de Cebrián (2001: 15-20), Pallet, Link y Lee (2010: 151-153) y los modelos de estudio de Fanjul (2007: 410-412), se analizan a continuación la apariencia física, los artefactos y la personalidad de los principales protagonistas de la serie (los más reconocidos y premiados).

\subsection{Análisis de personajes}

Lea Michele (Rachel Berry, en la serie) representa el papel de una chica judía con un gran don vocal, que en público se muestra tímida, con poca autoestima, pero enamorada del chico más popular del instituto; el capitán del equipo de fútbol americano Finn Hudson (Cory Monteith). Para encajar con credibilidad en este papel, era importante que el aspecto físico de la actriz se adecuara con el estereotipo del personaje. A continuación se analizan sus rasgos físicos: 


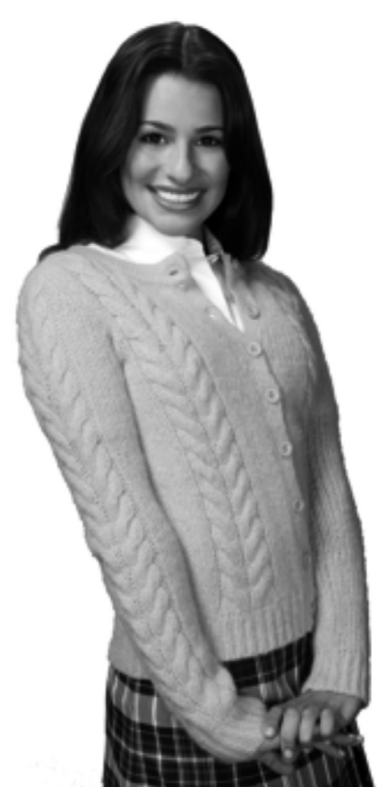

\begin{tabular}{|l|l|}
\hline LEA MICHELE (RACHEL BERRY) \\
\hline Constitución corporal & Ectomorfa con cierto grado de mesoformismo \\
\hline Modelo & Fitness \\
\hline Proporción facial & Alargada, estrecha, curviforme, rasgos suaves \\
\hline Pelo & Fino, largo, liso, moreno, peinado con raya \\
\hline Frente & Amplia, lisa, limpia \\
\hline Cejas & Arqueadas, perfiladas, separadas, finas \\
\hline Ojos & Medianos, arqueados, marrones, limpios \\
\hline Nariz & Recta, redondeada, grande, ancha \\
\hline Boca/labios & Recta, grande, labios carnosos \\
\hline Mejillas/pómulos & Prominentes, angulosos, tersos, limpios \\
\hline Mentón/barbilla & Redondeado, no partida, sin hoyo, mediana \\
\hline Barba & Sin barba \\
\hline Orejas & Proporcionadas, un poco separadas, lóbulo mediano \\
\hline Piel & Blanca, tersa, limpia \\
\hline
\end{tabular}

Como se puede observar, el aspecto físico empasta perfectamente con el estereotipo, la personalidad y los valores del personaje definido para la trama. Al tratarse de una chica judía, la modelo a encontrar tenía que ser morena o castaña y con una nariz peculiar (además, en la serie, la protagonista tiene como referente a alcanzar a Barbra Streisand). Poseer una belleza tamizada (sutil) pero presente, con una constitución corporal acorde a los cánones de belleza establecidos pero no exagerados. Personalmente, debía plasmar tener sueños (esperanzas) pero con un camino difícil por delante para alcanzarlos. Y debía de mostrarse tímida en público pero segura a la hora de cantar y expresar vocalmente sus sentimientos y aspiraciones; con capacidad pero débil ante una sociedad (instituto) que la rechaza constantemente por ser diferente.

Los artefactos que Lea porta en la serie, realzan estos rasgos de personalidad: siempre son prendas clásicas (chaquetas de punto, camisas o suéter de cuello alto, faldas plisadas, manoletinas como calzado, etc.), collares de oro fino y pendientes de perla. Los colores de sus ropas son siempre pasteles u oscuros (poco llamativos). Y constantemente la vemos andando por los pasillos del instituto abrazada a un cuaderno o un libro (signo de autoprotección y timidez).

La antagonista de Rachel Berry será Quinn Fabray (interpretada por Dianna Agron), la capitana de los animadores, de complexión atlética, con una belleza estereotipada (rubia, delgada, ojos claros y facciones suaves) y con personalidad soberbiosa y altiva que va a enfrentarse a Rachel por el amor y la admiración de Finn. 
Por su parte, Cory Monteith (Finn Hudson en la serie) interpreta al quarterback del equipo del instituto; alguien popular y deseado por la mayoría de las estudiantes. Le cuesta aceptar lo que implica su pasión por la música y el canto, ya que entrar en el Glee Club le supone la pérdida de popularidad y el rechazo. Pero acaba enfrentándose a sus temores y luchando por aquello que desea. Seguidamente, se analizan sus características físicas siguiendo el mismo modelo y parámetros:

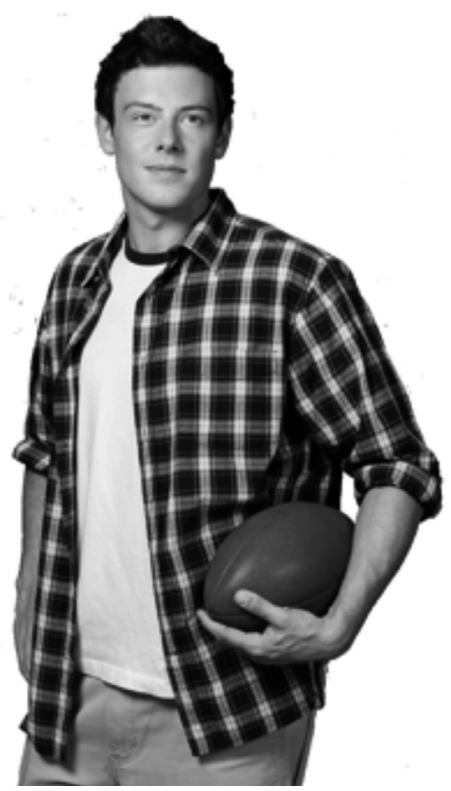

\begin{tabular}{|l|l|}
\hline CORY MONTEITH (FINN HUDSON) \\
\hline Constitución corporal & Mesomorfo \\
\hline Modelo & Fitness \\
\hline Proporción facial & Alargada, estrecha, curviforme, rasgos suaves \\
\hline Pelo & Grueso, corto, ondulado, castaño, despeinado \\
\hline Frente & Amplia, lisa, limpia \\
\hline Cejas & Arqueadas, pobladas, separadas, gruesas \\
\hline Ojos & Pequeños, arqueados, pardos, limpios \\
\hline Nariz & Perfilada, recta, pequeña, bien formada \\
\hline Boca/labios & Recta, mediana, labios gruesos \\
\hline Mejillas/pómulos & Poco prominentes, suaves, tersos, limpios \\
\hline Mentón/barbilla & Redondeado, no partida, pequeño hoyuelo, mediana \\
\hline Barba & Sin barba \\
\hline Orejas & Grandes, un poco separadas, lóbulo grande \\
\hline Piel & Blanca, tersa, con pocas pecas \\
\hline
\end{tabular}

La constitución y el rostro del actor Cory Monteith, responde al modelo estándar de belleza masculina; atlética, con músculos definidos (pero no exagerados) y con una cara varonil pero con rasgos suavizados y aniñados. Este aspecto físico, se adapta bien al rol y personalidad del personaje en la serie; un chico con éxito, que se erigirá como líder del Glee Club, pero con un lado sensible, cariñoso y amable. En su rol de capitán del equipo de fútbol, el personaje viste el uniforme que luce con orgullo al proporcionarle admiración y deseo. Cuando no lo lleva, utiliza ropa cómoda, de corte deportivo (camisetas, sudaderas) o camisas desabotonadas (estilo informal).

Chris Colfer es el actor que da vida a Kurt Hummel, un chico abiertamente homosexual que es constantemente ridiculizado y vilipendiado por su orientación y forma de vestir. El personaje tendrá que mostrar ser fuerte ante los ataques para defenderse y no avergonzarse de lo que es, aunque sufre momentos de debilidad y frustración ante el rechazo. Cantar e interpretar es su sueño y dentro del grupo Glee se siente completo. Sus características físicas son las siguientes: 


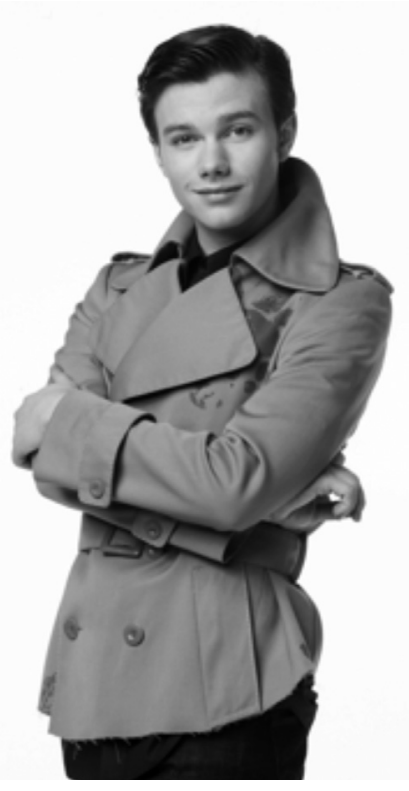

\begin{tabular}{|l|l|}
\hline CHRIS COLFER (KURT HUMMEL) \\
\hline Constitución corporal & Mesomorfo con cierto grado de ectomorfismo \\
\hline Modelo & Fitness/Andrógino \\
\hline Proporción facial & Alargada, ancha, curviforme, rasgos suaves \\
\hline Pelo & Fino, intermedio, liso, pelirrojo, peinado \\
\hline Frente & Amplia, lisa, limpia \\
\hline Cejas & Arqueadas, perfiladas, separadas, gruesas \\
\hline Ojos & Medianos, arqueados, azules, limpios \\
\hline Nariz & Recta, chata, grande, ancha \\
\hline Boca/labios & Ovalada, grande, labios gruesos \\
\hline Mejillas/pómulos & Prominentes, suaves, tersos, limpios \\
\hline Mentón/barbilla & Anguloso, partida, sin hoyo, mediana \\
\hline Barba & Sin barba \\
\hline Orejas & Proporcionadas, pegadas, lóbulo grande \\
\hline Piel & Blanca, tersa, con pocas pecas \\
\hline
\end{tabular}

El aspecto físico del actor (con rasgos más femeninos) dotan de credibilidad y fuerza al personaje de Kurt. De constitución aparentemente débil, disfraza esta debilidad con arrogancia y poca vergüenza al vestir ropas y complementos muy llamativos y fuera de lo "normalizado" (como expresión de ruptura u oposición con lo establecido); siempre prendas de marcas de moda o que se diseña él mismo. Sus rasgos faciales (nariz, boca, mentón) facilitan la expresión de altivez en los momentos que tiene que mostrarse duro o poco afectado, y de debilidad y tristeza (ojos, cejas, formas suaves) al hacerle daño en sus sentimientos.

En la segunda temporada, Kurt conocerá a quien será su pareja sentimental en la serie, Blaine Anderson (interpretado por Darren Criss), cuyas características físicas responden más a las establecidas en los cánones estandarizados de belleza masculina (mesoformo con rasgos angulosos, frente a los suaves y más afeminados de Chris Colfer), pero que expresa su orientación por el tipo de ropas y complementos que utiliza, que sin ser tan radicalmente opuestos a lo normalizado como las de su compañero, también se alejan de lo estandarizado (chalecos, pajaritas, pantalones pesqueros).

Mark Salling interpreta a Noah Puckerman en la serie. Él es un rebelde, un abusador poco amigo de los estudios y que presume de haberse acostado con casi todas las estudiantes del instituto. Su origen judío y haberse criado en el seno de una familia desestructurada le coloca en el punto de mira de los señalados socialmente, según pero lo evita con la actitud de 
matón y ligón que intenta mantener a toda costa. Al principio, ve el Glee Club como un castigo, pero poco a poco comprobará que gracias a él madura como persona. Sus características físicas son:

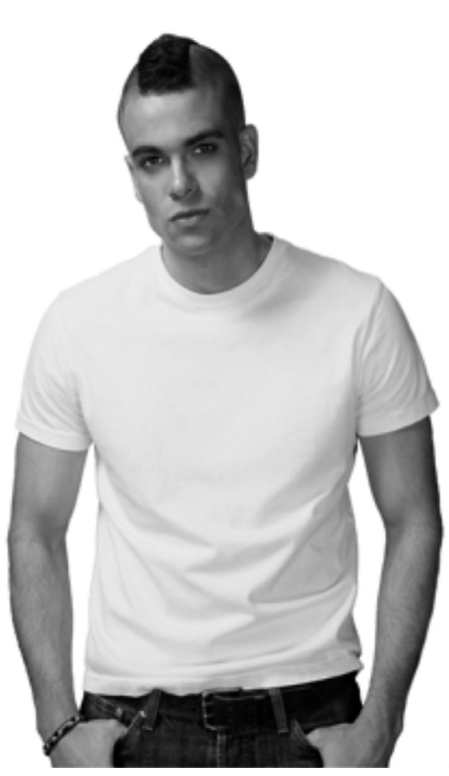

\begin{tabular}{|l|l|}
\hline \multicolumn{2}{|l|}{ MARK SALLING (NOAH PUCKERMAN) } \\
\hline Constitución corporal & Mesomorfo \\
\hline Modelo & Fitness \\
\hline Proporción facial & Alargada, estrecha, angulosa, rasgos duros \\
\hline Pelo & Grueso, corto, ondulado, moreno, punkie \\
\hline Frente & Amplia, lisa, limpia \\
\hline Cejas & Arqueadas, pobladas, separadas, gruesas \\
\hline Ojos & Medianos, arqueados, pardos, limpios \\
\hline Nariz & Recta, redondeada, proporcionada, bien formada \\
\hline Boca/labios & Ovalada, pequeña, labios carnosos \\
\hline Mejillas/pómulos & Prominentes, angulosos, tersos, limpios \\
\hline Mentón/barbilla & Cuadrado, no partida, sin hoyo, mediana \\
\hline Barba & Sin barba \\
\hline Orejas & Grandes, pegadas, lóbulo grande \\
\hline Piel & Blanca, tersa, limpia \\
\hline
\end{tabular}

El aspecto físico de Mark Salling empasta a la perfección con los orígenes étnicos y la personalidad definida para el personaje. Las facciones angulosas y marcadas de su rostro, junto con un corte de pelo rapado a lo punk, dota a Noah Puckerman de una imagen de chico duro, varonil y atractivo que le hace ser temido por unos y deseado por otras. La ropa y artefactos que utiliza van acordes a esta personalidad; pantalones vaqueros, camisetas y cazadoras de cuero son las prendas que más utiliza, junto con una pulsera de piel como único complemento.

\section{Conclusiones generales y específicas}

Las investigaciones y estudios sobre el atractivo y valor comunicativo del rostro y la forma corporal, corroboran la concordancia estereotipada que está establecida entre el aspecto físico y el comportamiento esperado, aportando además variables y claves que esclarecen esa percepción inicial aportada únicamente por la imagen personal. Entre las conclusiones generales es preciso afirmar que:

a) El aspecto físico y los artefactos que lo complementan y modifican, son aspectos no verbales de la comunicación humana que ayudan en las series de ficción televisiva a definir y reforzar el carácter y la personalidad de los personajes de la narración. 
b) Estos códigos no verbales facilitan al telespectador el poder posicionar, configurar e identificar a cada uno de ellos en el entramado de la historia y su evolución conforme a un guion establecido previamente.

c) Aspectos como la clase social, estilo de vida, actitud vital, valores o forma de ser, se perfilan y consolidan a través de elementos tales como las características físicas, la ropa, los peinados o los complementos de moda utilizados. Cada uno de estos elementos tiene valor comunicativo y es necesario su estudio y correcta utilización en las series de ficción para dotar de mayor credibilidad y consistencia al personaje que se está representando.

Entre las conclusiones específicas tras el análisis de los protagonistas principales de la primera temporada de la serie "Glee" se han podido corroborar otros puntos entre los que destacan los siguientes:

a) Las características faciales y somáticas de los personajes estaban en consonancia con las actitudes y comportamientos que deben desarrollar los actores, y cómo los artefactos que estos portan ayudan a consolidar la personalidad de los mismos en la percepción del público.

b)La concordancia y simbiosis entre aspecto físico y carácter esperado se configura como un elemento más que influye y ayuda en la definición y construcción de los personajes de ficción.

c) La apariencia de los actores que van a interpretar los diferentes papeles es un aspecto que no está dejado al azar, sino que se busca, analiza y escoge en función del rol que va a desempeñar cada personaje dentro de la serie. De ahí, la importancia esencial de los procesos de casting; un aspecto no siempre valorado en las producciones audiovisuales por público y profesionales, pero que se erige como una de las piezas clave para el éxito y aceptación de las mismas.

En la serie Glee, la apariencia de los personajes, reforzada por los artefactos que estos portan, refuerzan los puntos clave sobre los que se va a desarrollar la historia argumental y sobre ellos van a ir "pivotando" el resto de historias y personajes. Esta investigación demuestra la importancia de una correcta representación de los aspectos no verbales de los personajes en la configuración de la credibilidad de la historia como pieza clave de la identificación y éxito de la misma. La verosimilitud se convierte en el factor que da realismo y credibilidad a las series de ficción, aumentando con ello su calidad, interés y aceptación por parte de los telespectadores.

\section{Referencias bibliográficas}

Albadalejo Mayordomo, T. (2013): “Retórica cultural, lenguaje retórico y lenguaje literario", Tonos Digital: Revista electrónica de estudios filológicos. n. 25, p. 21.

Baudouin, J. Y. \& Tiberghien, G. (2004):"Symmetry, averageness, and feature size in the facial attractiveness of women", Acta Psychologica, 117 (3), pp. 313-332. 
Bishop, R. (2000): "More than meets the eye: an exploration of literature related to the mass media's role in encouraging changes in body image", Communication yearbook, 23, pp. 271-303.

Cabezuelo Lorenzo, F. (2010):"La imagen del sueño americano: estética y modelos de belleza de la sociedad norteamericana a través de MadMen", Icono 14, vol. 8, núm. 3, pp. 97-117. http://dx.doi.org/10.7195/ri14.v8i3.231 [Consultado el $1 / 10 / 2014]$.

Canet, F. (2009): Narrativa audiovisual. Estrategias y recurso. Madrid: Síntesis.

Carrillo, M. V., Sánchez, M. \& Jiménez, M. (2011): “Factores socioculturales y personales relacionados con el mensaje mediático del culto al cuerpo influyentes en el bienestar de los jóvenes", Comunicación y Sociedad, vol. XXIV, n. 2, 2011, pp. 200-227.

Cassetti, F. \& Di Chio, F. (1999): Análisis de la televisión. Instrumentos, métodos y prácticas de investigación. Barcelona: Paidós.

Cebrián, M. (2001):"Aprender a ver y analizar la información audiovisual", Comunicar, 17, pp. 15-20.

Chen, A., German, C. \& Zaidel, D. (1996):"Brain asymmetry and facial attractiveness: facial beauty is not simple in the eye of the beholder", Neuropsychologia, 35(4), pp. 471-476.

Cortés, J. \& Gatti, F. (1965):"Physique and self-description of temperament", Journal of Consulting Psychology, 29, pp. 432439.

Costa, J. (2008): La Forma de las ideas. Cómo piensa la gente: Estrategias de la imaginación creativa. Barcelona: Autor-Editor.

Cunnigham, M., Barbee, A. \& Pike, C. (1990): "What do women want? Facialmetric assessment of multiple motives in the perception of male facial physical attractiveness", Journal of personality and social psychology, 59 (1), pp. 61-72.

Deneb, L. (2001): Diccionario de símbolos. Madrid: Biblioteca Nueva.

Eguizábal, R. \& Caro, A. (1996): Medición, investigación e información de la publicidad. Madrid: Comunicación 2000.

Fanjul-Peyró, C. (2007): La apariencia y características físicas de los modelos masculinos: códigos no verbales de la realidad en el discurso publicitario, como factor de influencia social mediática en la vigorexia masculina, Universitat Jaume I, Castellón, 2007. http://www.tdx.cat/TDX-0301107-154815/ [Consultado el 07/02/2014].

Fanjul-Peyró (2008): Vigorexia: una mirada desde la publicidad, Madrid: Fragua.

Fanjul-Peyró, C. \& González Oñate, C. (2012):"El rol de los códigos no verbales de la realidad en la creatividad del discurso publicitario", Doxa Comunicación, n. 14, pp.75-98.

Fernández Díez, F. \& Martínez Abadía, J. (1999): Manual básico del lenguaje y narrativa audiovisual. Barcelona: Paidós. 
Fisher, M. \&Voracek, M. (2006):"The shape of beauty: determinants of female physical attractiveness", Journal of cosmetic dermatology, 5(2), pp. 190-194.

García García, F. (2003):"Posibilidades creativas de la imagen", Icono 14, n. 2, pp. 9-25.

García García, F. (2006): Narrativa Audiovisual. Madrid: Editorial Laberinto.

Garin, M. (2013): “Truth Takes Time: the interplay between Heroines, Genres and Narratives in three J. J. Abrams' Television Series", Comunicación y Sociedad, Vol. XXVI, n. 2, pp.47-64.

Gordillo, I. (2009): Manual de narrativa televisiva, Madrid: Síntesis.

Guerrero, J. (2004): “El mercado de la identidad corpórea y sus contornos emocionales”, Razón y Palabra, 39. http://www.razonypalabra.org.mx/anteriores/n39/jguerr.html [Consultado el 1/10/2014].

Hendricks, C., Olson, D., Hall, S. \& Batt, J. (1998): “Cultural aspects of physical attraction”, Advanced Social Psychology, pp. 324.

Hervás, G. (1998): Cómo dominar la comunicación verbal y no verbal. Madrid: Playor.

Knapp, M. (1995): La comunicación no verbal. El cuerpo y el entorno. Barcelona: Paidós.

Lanuza Avello, A. (2011): El hombre intranquilo. Mujer y maternidad en el cine clásico americano. Madrid: Editorial Encuentro.

Lorenzo, J. (2000): Comunicación no verbal. Periodismo y medios audiovisuales. Madrid: Editorial Universitas.

Martínez Lucena, J. (2009): “El cine multi-protagonista: autenticidad, lenguajes sutiles y lotta continua”, Observaciones Filosóficas, n. 9.

Mills, J. \& Aronson, E. (1965): “Opinion change as a function of the communicator's attractiveness and desire to influence”, Journal of Personality and Social Psychology, 1(2), pp. 73-77.

Orellana Gutiérrez de Terán, J. (2012): "Las mixtificaciones narrativas en el cine de Alejandro González Iñárritu”, en Comunicación: Revista Internacional de Comunicación Audiovisual, Publicidad y Estudios Culturales, n. 10. pp. 1158-1171.

Orellana Gutiérrez de Terán, J. \& Martínez Lucena, J. (2010): Celuloide posmoderno. Madrid: Editorial Encuentro.

Pallet, P., Link, S. \& y Lee, K. (2010): “New “golden” ratios for facial beauty”, Vision Research, 50 (2), pp. 149-154.

Pérez Gauli, J. C. (2000): El cuerpo en venta. Madrid: Cátedra.

Rosales, E. (2002): Estética y medios de comunicación. Madrid: Tecnos.

Segado Boj, F. \& Barquero Cabrero, M. [Eds.] (2013): Persuasión Audiovisual. Formas, soportes y nuevas estrategias. Madrid: McGrawHill, Furtwangen Editores \& ESERP. 
Serrano Oceja, J. F. (2012): “De la Retórica a la Periodística”, en Del Río Sanz, E. y et alt: Retórica y política: los discursos de la construcción de la sociedad. Logroño: Instituto de Estudios Riojanos Publicaciones, pp. 683-698.

Sheldon, W. (1954): Atlas of man: a guide for somatyping the adult male at all ages. Nueva York: Harper \& Row.

Sheldon, W. \& Stevens, S. (1951): Les variétés du tempérament. Une psychologie des différences constitutionnelles. Paris: Presses Universitaires de France.

Wainwright, G. (1991): El lenguaje del cuerpo. Madrid: Pirámide.

Watzlawick, P., Beavin J. \& Jackson, D. (2002): Teoría de la Comunicación Humana. Barcelona: Herder.

Widgery, R. \&Webster, B. (1969): “The Effects of Physical Attractiveness upon Perceived Initial Crediblility”, Michigan Speech Journal, 4, pp. 9-15. 